\title{
Application of the Dynamic Compaction Method for Ground Improvement of Collapsible Loess in Qinhai
}

\author{
Jun CAI ${ }^{1}$ \\ Jingtao ZHANG ${ }^{2}$ \\ Guangyin DU ${ }^{3}$ \\ Han XIA ${ }^{4}$
}

\begin{abstract}
The collapsibility of loess has a great influence on subgrade construction in Qinghai, China, so laboratory tests are utilized to evaluate the collapsibility influencing factors, which illustrates that the collapsibility of this region is not dominated by soluble salts but an alkaline environment, high porosity and a low water content. The in situ self-weight submerging test reveals the settlement regularities, with a maximum settlement of $22.4 \mathrm{~cm}$, which suggests that the soil in the test region is self-weight collapsible loess. In consideration of the economy and applicability, dynamic compaction was chosen as the ground improvement method. The optimal number of drops $(N)$ for an energy level of $1000 \mathrm{kN} \cdot \mathrm{m}$ is 6 , and for the energy levels of $1500 \mathrm{kN} \cdot \mathrm{m}$ and $2000 \mathrm{kN} \cdot \mathrm{m}, N$ is 8 . Besides the maximum effective depth for $1000 \mathrm{kN} \cdot \mathrm{m}$ is $5-6 \mathrm{~m}$, and it is $6-7 \mathrm{~m}$ for $1500 \mathrm{kN} \cdot \mathrm{m}$ and $2000 \mathrm{kN} \cdot \mathrm{m}$.
\end{abstract}

Keywords: Loess, collapsibility, ground treatment, dynamic compaction.

\section{INTRODUCTION}

Loess accounts for $9.3 \%$ of the land area in the world and $3 \%$ in Asia. In China, loess is also widely distributed in Qinghai, Ningxia, Shaanxi and Inner Mongolia [1]. Loess is a yellow powdery soil formed during the quaternary period, with a high porosity, its structure is sensitive to water. When loess is eroded by water, the structure of the soil will rapidly be damaged, and the bearing capacity of the foundation will decrease quickly with settlement.

\section{Note:}

- This paper was received on May 30, 2019 and accepted for publication by the Editorial Board on June 26, 2020.

- Discussions on this paper will be accepted by March 31, 2022.

- https://doi.org/10.18400/tekderg.571877

1 Southeast University, Institute of Geotechnical Engineering, Nanjing, China - caijun129@seu.edu.cn https://orcid.org/0000-0001-9569-7418

2 CCCC First Highway Consultants Co, Ltd., Xi’an, China - 646772644@qq.com https://orcid.org/0000-0002-3102-6751

3 Southeast University, Institute of Geotechnical Engineering, Nanjing, China - guangyin@seu.edu.cn https://orcid.org/0000-0002-1253-5761

4 Southeast University, Institute of Geotechnical Engineering, Nanjing, China - imxiahan@hotmail.com https://orcid.org/0000-0001-7575-1392 
The collapsible settlement of loess is a kind of hazard, resulting in large settlement or differential settlement, cracking, inclination and damage. If it is not treated properly, engineering problems may occur.

The main features of loess are its structural properties and collapsibility, and these two characteristics are closely related [2]. The influencing factors of loess collapsibility can be complicated, and some laboratory tests [3-9] on the relationship between collapsibility and soil physical-mechanical parameters have been studied, among which the soluble salt, water content, void ratio and dry density are the high relative factors. As the performance of the in situ soaking test can be closer to that of the actual situation, valuable settlement regularity and collapsibility evaluations can be acquired, so the tests were conducted on different scales [10-14], and prominent loess collapsible features were found.

Because of the poor properties of collapsible loess, reasonable and effective treatments are needed for construction in loess regions. The most common methods are dynamic compaction, compaction pile and pre-soaking methods, among which dynamic compaction is most widely used and economical. Lyu [15] and Xing [16] provided suggestions about the dynamic compaction parameters for collapsible loess treatment. Zhan [17] presented an empirical formula for the treating depth of dynamic compaction in Gansu, China. For different collapsible loess layer thicknesses, Huang [18] proposed the foundation treatment depth and remaining collapsible settlement standards. Hu [19] acquired the optimum centre distance of dynamic compaction in Lishi, China.

These achievements have made great contributions to infrastructure construction in loess regions; as for the particularity of loess in different regions, more loess parameters and dynamic compaction parameters are still needed. Therefore, for the construction of a highgrade highway subgrade in Qinghai Province, a series of tests on collapsible loess properties and dynamic compaction parameters have been conducted, which can be valuable for the treatment of loess.

\section{LOESS PROPERTIES}

\subsection{Geological Conditions}

The test site is located in Huangyuan County of Xining city (Fig. 1a). The geological investigation report reveals that the main constituents of the loess are silt and clay, (Fig. 1b), and it contains developed pores; the collapsible loess depth exceeds $10 \mathrm{~m}$. The groundwater level is over $20 \mathrm{~m}$ below the surface, so the influence of underground water does not need to be considered.

The main property of loess is its collapsibility, with the influence of gravity stress or additional stress from overlaying soil. When natural loess is eroded by water, the soil structure is rapidly damaged, and significant settlement occurs. According to the Chinese Technical Code [20], the collapsibility coefficient is defined by (1):

$$
\delta_{\mathrm{s}}=\frac{h_{\mathrm{p}}-h_{\mathrm{p}}^{\prime}}{h_{0}}
$$


where $h_{\mathrm{p}}$ is the height of the soil sample $(\mathrm{cm})$ when the soil settlement is stable under a certain pressure condition $(p)$ with a natural soil water content and structure; $h_{\mathrm{p}}$ ' is the height of the soil sample $(\mathrm{cm})$ when it is immersed in water and the settlement is stable; and $h_{0}$ is the original height of the soil $(\mathrm{cm})$. For the pressure condition $(p)$ of formula (1) in the collapsibility coefficient test, when the soil sampling depth is $0-10 \mathrm{~m}$ under the bottom of the base, $p$ is $200 \mathrm{kPa}$; when the soil sampling depth is beyond $10 \mathrm{~m}, p$ is the saturated selfweight pressure of the overlying soil (if $p$ is over $300 \mathrm{kPa}, p$ is $300 \mathrm{kPa}$ ). When $\delta_{\mathrm{s}}<0.015$, the soil sample is non-collapsible loess, and when $\delta_{\mathrm{s}} \geq 0.015$, the soil is collapsible loess.

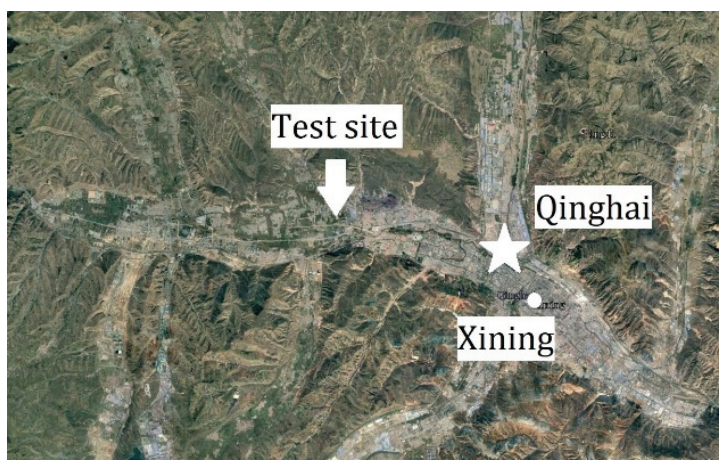

(a) Satellite Map (http//:map.bing.com)

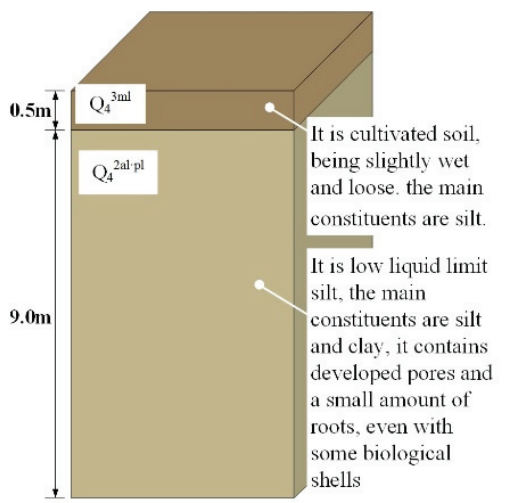

(b) Soil Profile

Figure 1 - Geological Condition of the Test Site

Table 1 shows the physical parameters of the loess and that the loess contains developed pores. Particle size analysis shows that the loess in this region is mainly composed of silt particles $(0.05 \sim 0.005 \mathrm{~mm})$, accounting for $62-63 \%$ of the total content.

Table 1 - Physical Parameters of the Loess

\begin{tabular}{cccccc}
\hline $\begin{array}{c}\text { Unit weight } \\
/ \gamma\left(\mathrm{kN} / \mathrm{m}^{3}\right)\end{array}$ & $\begin{array}{c}\text { Dry unit } \\
\text { weight } \\
/ \gamma_{\mathrm{d}}\left(\mathrm{kN} / \mathrm{m}^{3}\right)\end{array}$ & $\begin{array}{c}\text { Water } \\
\text { content } \\
/ w(\%)\end{array}$ & $\begin{array}{c}\text { Void ratio } \\
/ \text { L }\end{array}$ & $\begin{array}{c}\text { Liquid limit } \\
/ w_{\mathrm{L}}(\%)\end{array}$ & $\begin{array}{c}\text { Plasticity } \\
\text { index } \\
/ I_{\mathrm{P}}(\%)\end{array}$ \\
\hline 17.2 & 15.1 & 16.4 & 0.81 & 25.1 & 6.9 \\
\hline
\end{tabular}

\subsection{Soluble Salt}

Table 2 shows the analysis of soluble salt in soil. The $\mathrm{pH}$ of collapsible loess in Qinghai is between 7.3 and 7.5, and it is slightly alkaline. As organic matter in soil is acidic, flocculent organic matter can be easily dissolved in alkaline environments [21], which causes the porosity to increase and the loess in Qinghai to easily collapses. 
Table 2 - Soluble salt in loess (unit: $\mathrm{mg} / \mathrm{kg}$ )

\begin{tabular}{cccc}
\hline Depth/m & 1 & 2.5 & 4 \\
\hline $\mathrm{pH}$ & 7.5 & 7.3 & 7.5 \\
$\mathrm{HCO}^{3-}$ & 348.7 & 320.8 & 432.3 \\
$\mathrm{Cl}^{-}$ & 64.46 & 119.71 & 119.71 \\
$\mathrm{SO}_{4}^{2-}$ & 137.8 & 137.8 & 275.5 \\
$\mathrm{~K}^{+}$ & 5.35 & 6.30 & 10.35 \\
$\mathrm{Na}^{+}$ & 21.90 & 16.65 & 21.90 \\
$\mathrm{Ca}^{2+}$ & 137.9 & 126.49 & 137.99 \\
$\mathrm{Mg}^{2+}$ & 48.84 & 34.89 & 69.77 \\
Salinity & 710.0 & 730.0 & 990.0 \\
\hline
\end{tabular}

Aeolian deposition is the dominant factor for loess deposition in Western China. Wind causes silt particles to accumulate loosely on the ground, and less rainfall infiltration causes soluble salt to dissolve and recrystallize; thus, the soil particle connections are not dominated by mechanical friction but rather soluble salt chemical links. Soluble salt plays an important role in the loess structure [22]. Research shows that when the content of soluble salt in soil is less than $0.50 \%$, the soluble salt has little effect on the compactness and shape of loess [22]; the content of soluble salt in Qinghai is $0.052 \%-0.15 \%$, which is far less than $0.5 \%$, so the collapsibility of this region is not dominated by soluble salts.

\subsection{Water Content}

In Fig. 2, for the laboratory test results, a curve with a high fitting coefficient cannot be obtained, so an obvious relationship between the collapsibility and water content is not

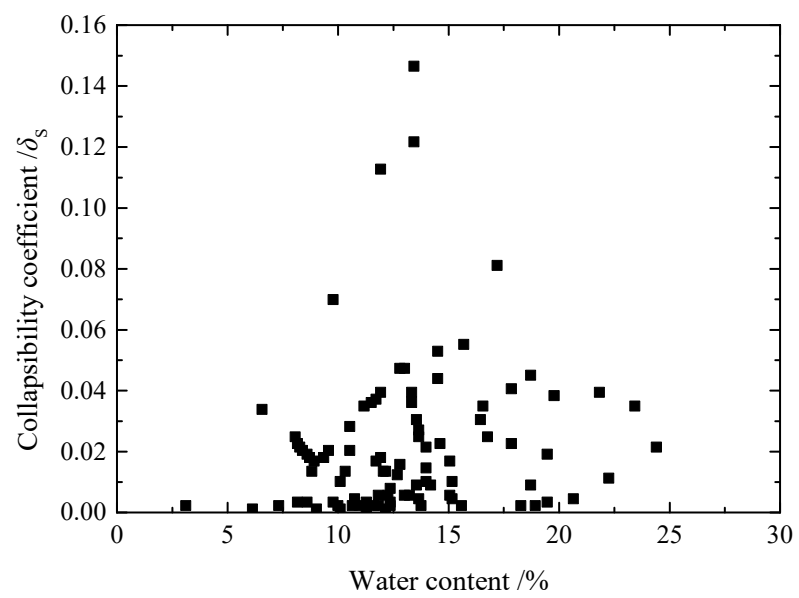

Figure 2 - Relationship between the Collapsibility Coefficient and Water Content 
available. But considering the collapsibility mechanism of loess, when loess is immersed in water under stress, collapsible failure occurs, so the influence of water content on loess collapsibility exists. It may be that the collapsibility coefficient not only related to water content, Liu [23] believes that the motivations of loess collapsibility are stress and water, there is no linear correlation between water content and collapsibility. With different sampling depth, the stress and sedimentary state of samples are different, which results in different collapsibility, besides the water content is affected by environmental precipitation. So loess collapsibility coefficient may not have a certain correlation with water content, it is also found by Lin [24] and Wang [25].

\subsection{Void Ratio}

The void ratio of loess soil reflects its density, and the void ratio is defined as (2):

$e=\frac{V_{v}}{V_{s}}=\frac{d_{s}(1+w) \rho_{w}}{\rho}-1$

Where $V_{\mathrm{v}}$ is the volume of the voids in the soil, $V_{\mathrm{s}}$ is the volume of the soil particles, $d_{\mathrm{s}}$ is the relative density of the soil particles, $w$ is the water content, $\rho_{\mathrm{w}}$ is the density of water, $\rho$ is the density of the soil, and $e$ is the void ratio, which can be calculated by these parameters.. In Fig. 3, after eliminating some discrete points, it shows that the collapsibility coefficient of collapsible loess increases exponentially with the void ratio. When collapse occurs, the porous granular structure is destroyed. The larger the void ratio is, the greater the coefficient of collapsibility becomes.

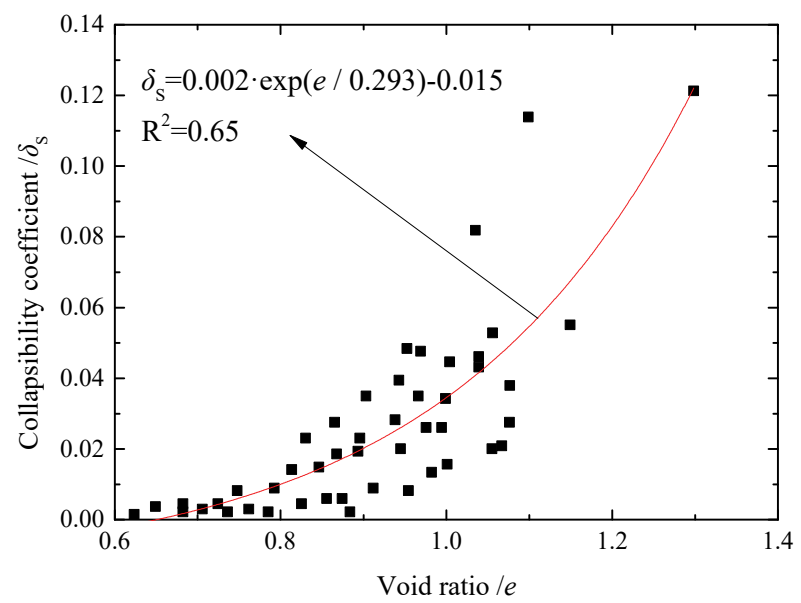

Figure 3 - Relationship between the Collapsibility Coefficient and Void Ratio

\subsection{Dry Unit Weight}

In Fig. 4, by eliminating some discrete results, the curve was fitted, with the increase in the dry unit weight $\left(\gamma_{\mathrm{d}}\right)$, the collapsible loess shows an exponentially decreasing trend. The larger 
the dry unit weight is, the denser the loess structure becomes, and the collapsibility becomes weaker.

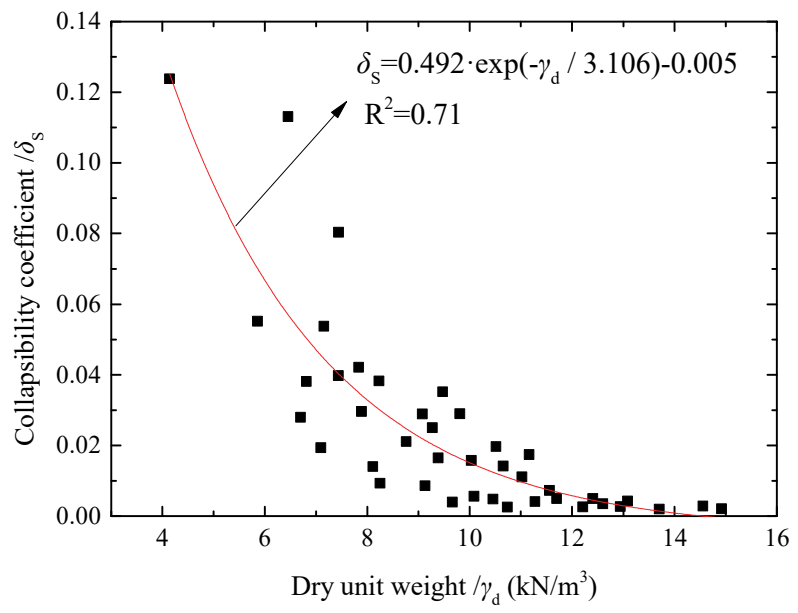

Figure 4 - Relationship between the Collapsibility Coefficient and Dry Unit Weight

\section{LOESS COLLAPSIBILITY IN SITU TESTS}

At present, there are two main methods for acquiring the collapsibility of loess: one is sampling the undisturbed soil and conducting the uniaxial immersion compression test to obtain the collapsibility coefficient, while the other is performing the in situ submerging test, with either the self-weight submerging test (SWST) or load submerging test (LST).

\subsection{Self-Weight Submerging Test (SWST)}

A square or circle test pit is needed for the self-weight submerging test, and the length of the pit must be longer than the depth of the collapsible loess soil thickness and be no less than $10 \mathrm{~m}$. The geologic report shows that the collapsible loess depth is $9.5 \mathrm{~m}$, so the width of the testing pit is $10 \mathrm{~m}$, and the depth is $0.5 \mathrm{~m}$. For the convenience and accuracy of the observations, the bottom elevation difference does not exceed $2 \mathrm{~cm}$, and coarse sand was paved as the bottom levelling layer, with the thickness of the layer being $10 \mathrm{~cm}$.

For the settlement observation at different depths, observation rods were arranged on the surface of the pit and inserted into the soil at depths of $0.5 \mathrm{~m}, 1.5 \mathrm{~m}$ and $2.5 \mathrm{~m}$. For the stability of the rods on the surface, concrete pedestals $(15 \mathrm{~cm} \times 15 \mathrm{~cm} \times 15 \mathrm{~cm})$ were fixed at the bottom. In the test, water level indicators were used around the test pit to maintain a water depth of $40 \mathrm{~cm}$. To avoid the influence of water erosion, a water injection hole was set and filled with pebbles, while the water inflow velocity was controlled during the process. Fig. 5 shows the monitoring point distribution in the SWST. 


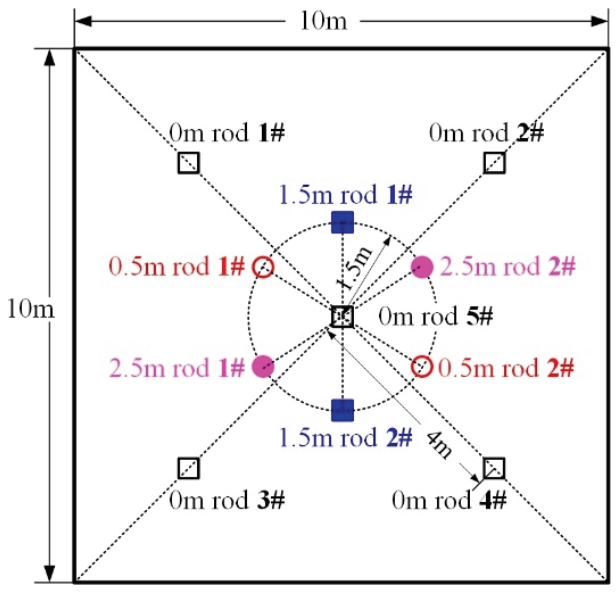

(a) Rod Arrangement

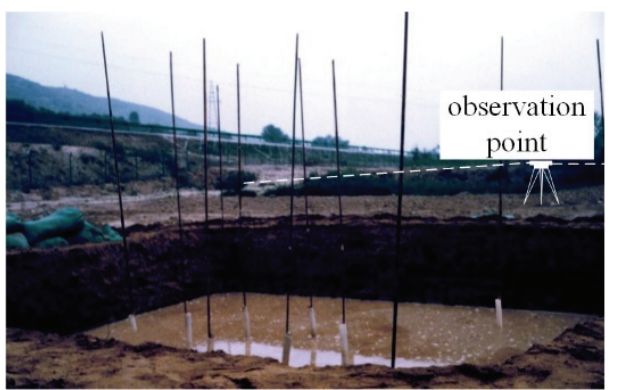

(b) Test Site

Figure 5 - Self-weight Submerging Test

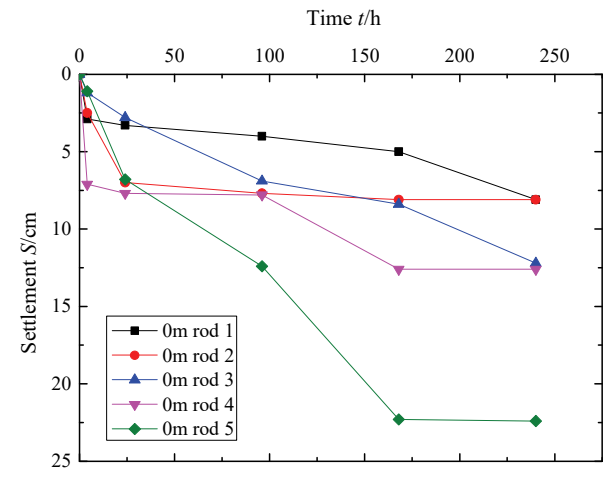

(a) $0 \mathrm{~m}$

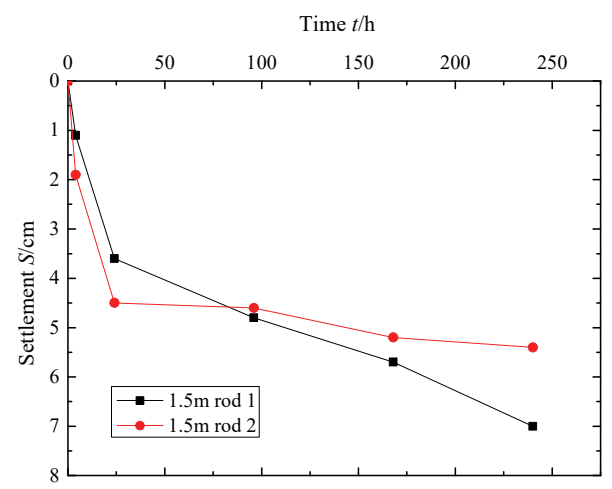

(c) $1.5 \mathrm{~m}$

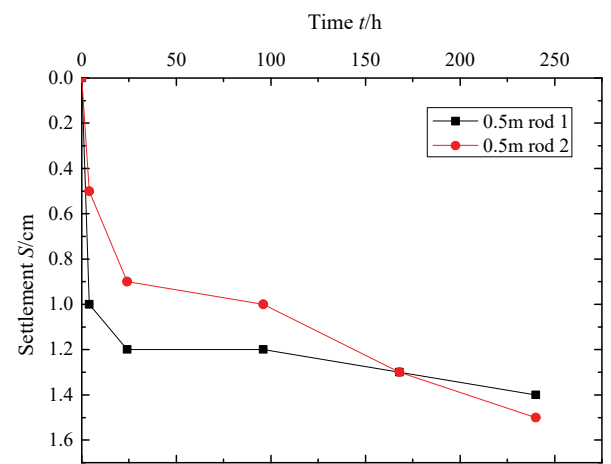

(b) $0.5 \mathrm{~m}$

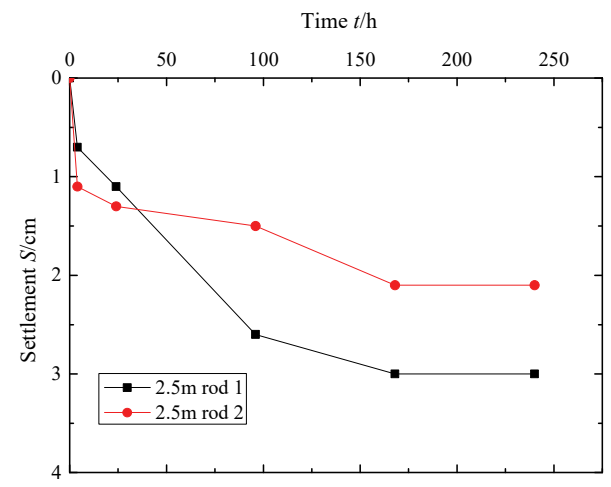

(d) $2.5 \mathrm{~m}$

Figure 6 - Rod Settlement at Different Depths for the SWST 
In the initial phase of the test, the settlement was obvious. After 4 h, 2 cracks appeared around the pit; after $24 \mathrm{~h}$, large annular cracks formed around the testing pit, the average length was $27 \mathrm{~cm}$, and water infiltrated into the pit wall at approximately $31 \mathrm{~cm}$. After $96 \mathrm{~h}$, for the majority of the monitoring points, the settlement was over $50 \%$ of the total settlement, and some points reached $70 \%$. At $240 \mathrm{~h}$, the settlement of all the points became stable, and many cracks appeared around the test pit.

Fig. 6 indicates that the settlement of each place in the pit is different. In Fig. 6(a), for shallow rods, the maximum settlement is $22.4 \mathrm{~cm}$, which is at the centre of the pit $(0 \mathrm{~m}$ rod 5 in Fig. 5 ), and the minimum settlement is $8.1 \mathrm{~cm}$, which is close to the edge of the test pit. According to the Chinese Technical Code [20], the total self-weight collapsible settlement exceeds 70 $\mathrm{mm}$, so the soil is self-weight collapsible loess. Comparing the settlement of the rods at different depths (Fig. 5), with increasing depth, the self-weight collapsibility increases to a maximum at $1.5 \mathrm{~m}$ and then gradually decreases.

\subsection{Load Submerging Test (LST)}

The load submerging test was performed in a pit with a size of $3 \mathrm{~m} \times 4 \mathrm{~m} \times 0.5 \mathrm{~m}$ (Fig. 7), and rods were arranged in the same way as the SWST (Fig. 5). The loading plate was a square steel plate $(70.7 \mathrm{~cm} \times 70.7 \mathrm{~cm} \times 1.2 \mathrm{~cm})$ on the bearing platform with loading sandbags (Fig. 7). Before the loading procedure, the soil in the test pit was soaked in water for 10 days to make it saturated. The loading weight should not exceed $25 \mathrm{kPa}$ in each step, and the settlement was measured for each $100 \mathrm{kPa}$, producing a final loading weight of $300 \mathrm{kPa}$. Then, the settlement was measured $6 \mathrm{~h}$ and $24 \mathrm{~h}$ later. During the loading process, when the settlement was no more than $0.2 \mathrm{~mm}$ in $2 \mathrm{~h}$, an additional load was added. Throughout the test, the water depth was kept at $40 \mathrm{~cm}$.

During the test, at day 2, annular cracks and soil settlement occurred around the test pit, the average width of the cracks was $40-50 \mathrm{~cm}$, and the depth of water infiltration into the pit wall was approximately $50 \mathrm{~cm}$. After 10 days, the annular collapse around the test pit nearly stopped. After loading to $300 \mathrm{kPa}$, and after $24 \mathrm{~h}$, the settlement was stabilized, and the test was finished.
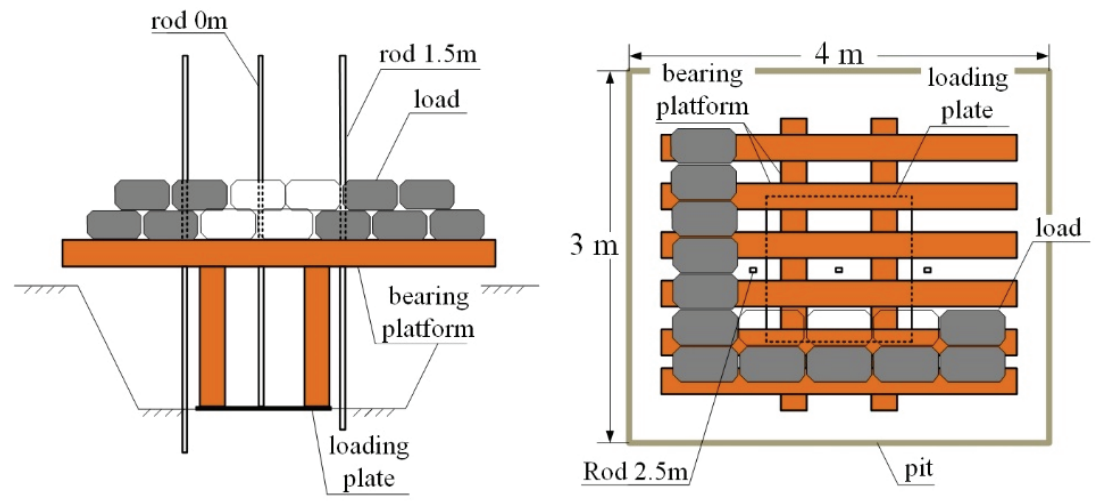

(a) Sketch of the Test 


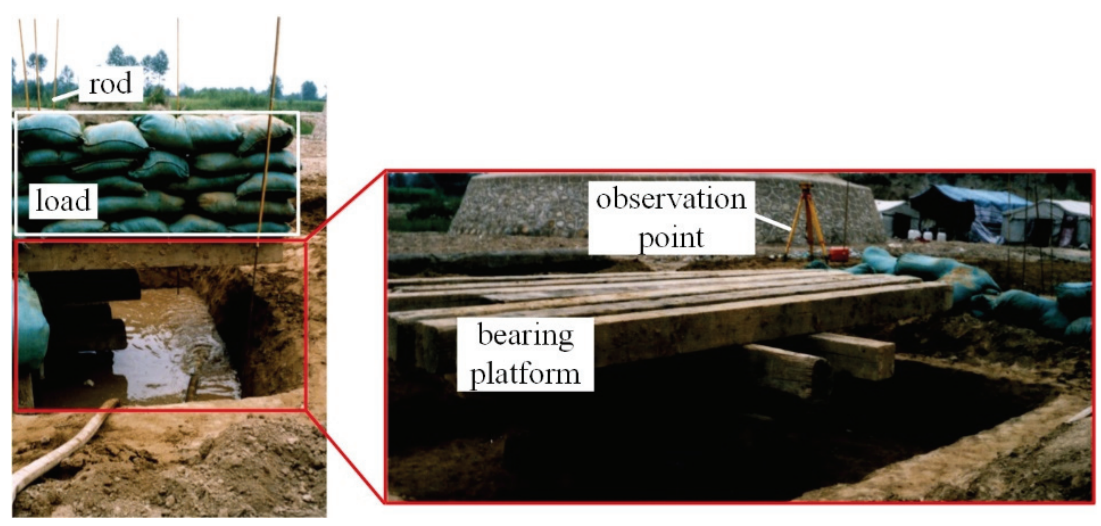

(b) Scene of the Site

Figure 7 - Load Submerging Test

Test process

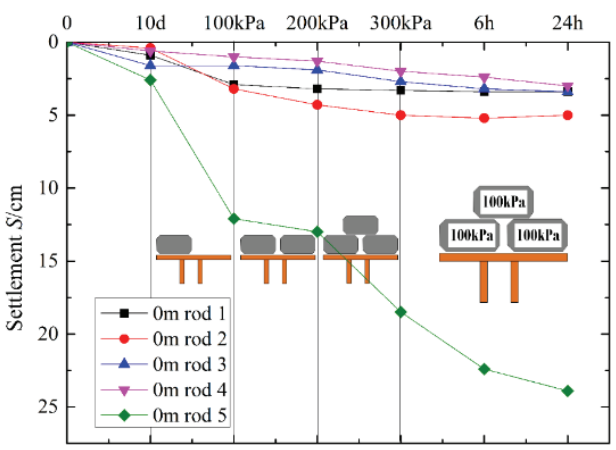

(a) $0 \mathrm{~m}$

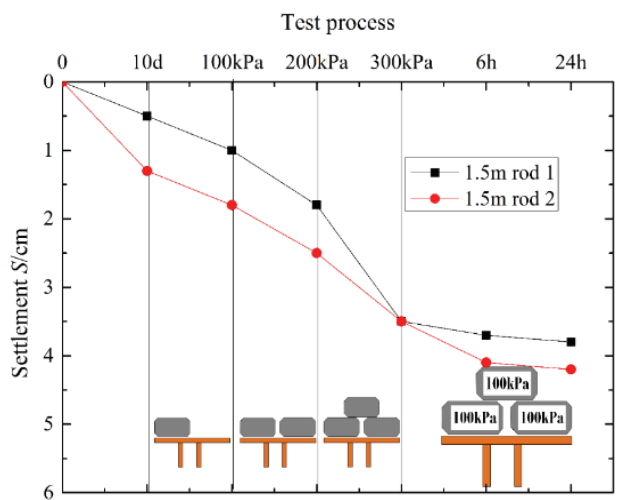

(c) $1.5 \mathrm{~m}$
Test process

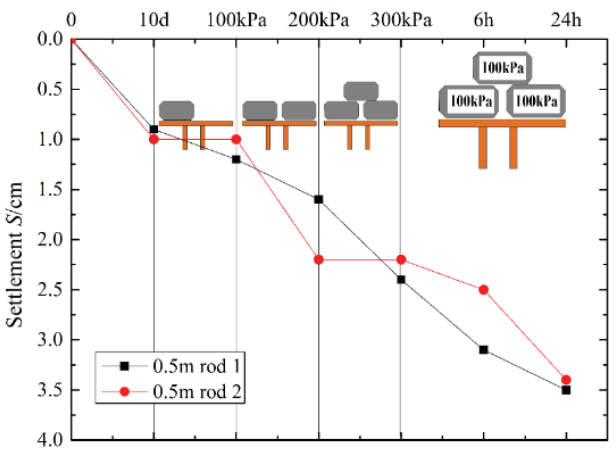

(b) $0.5 \mathrm{~m}$

Test process

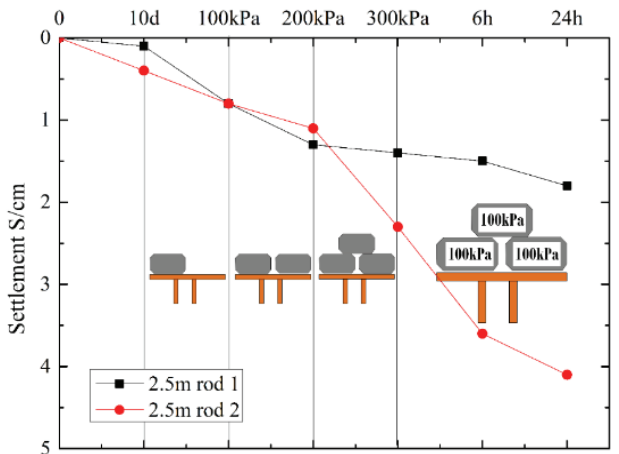

(d) $2.5 \mathrm{~m}$

Figure 8 - Rod Settlement at Different Depths for the LST 
Fig. 8 illustrates that the maximum settlement is in the centre of the loading plate with a depth of $0 \mathrm{~m}$, which is $23.9 \mathrm{~cm}$. After loading, the soil continues to collapse, so the settlement grows slowly. Compared with the SWST, the collapsible settlement is related to the area of the test pit; the larger the pit area is, the larger the settlement, which is also illustrated by Huang [26]. The collapsible settlement is also related to the additional stress, and the collapsible deformation is the total settlement of two factors: compressive deformation and collapsible deformation. The collapsible deformation can be divided into two stages: first, during the collapsible deformation stage, the loess structure is destroyed, and collapsibility occurs; second, during the reconsolidation stage, the pressure is constant, the soil particles rearrange, and the strength gradually increases as the collapsibility becomes stable.

\section{DYNAMIC COMPACTION METHOD AND APPLICATION}

The dynamic compaction method is illustrated in Fig. 9, and the compaction procedure is shown in Table 3. The hammer is cylindrical and made from cast iron with a diameter of 2.5 $\mathrm{m}$ and a weight of $13.5 \mathrm{t}$. The hoisting equipment is a crawler crane (Fig. 9). During compaction, compressional wave energy can be generated in the soil, which will squeeze the voids between soil particles. Therefore, the air in the soil particles is eliminated first, the particles are rearranged, and then the volume and plastic deformation of the soil reach a new stable state [27].

According to the Chinese Technical Code [28], the energy level division is based on the energy of each drop, so the compaction energy is calculated by (3) and divided into three levels: $1000 \mathrm{kN} \cdot \mathrm{m}, 1500 \mathrm{kN} \cdot \mathrm{m}$ and $2000 \mathrm{kN} \cdot \mathrm{m}$. The number of drops $(N)$ is set as 8,10 and 12, so the test can be categorized into 9 conditions (Fig. 10).

$E=M \cdot H$

where $E$ is the energy level of each drop $(\mathrm{kN} \cdot \mathrm{m}), M$ is the weight of the hammer $(\mathrm{kN})$, and $H$ is the height of the falling hammer.

Table 3 - Dynamic Compaction Procedure

\begin{tabular}{cl}
\hline Procedure & $\begin{array}{l}\text { Mark the grid point location on the levelling ground and measure } \\
\text { the elevation }\end{array}$ \\
\hline Step 1 2 & $\begin{array}{l}\text { Position the crane to ensure that the hammer is aligned with the } \\
\text { point }\end{array}$ \\
\hline Step 3 & $\begin{array}{l}\text { Lift the hammer to the designed height, free the hammer, and } \\
\text { measure the height of the hammer }\end{array}$ \\
\hline Step 4 & $\begin{array}{l}\text { According to the designed number of drops and control standards, } \\
\text { repeat step 3 to complete the compaction }\end{array}$ \\
\hline Step 5 & $\begin{array}{l}\text { Fill the compaction point with the bulldozer and measure the } \\
\text { ground elevation }\end{array}$ \\
\hline
\end{tabular}



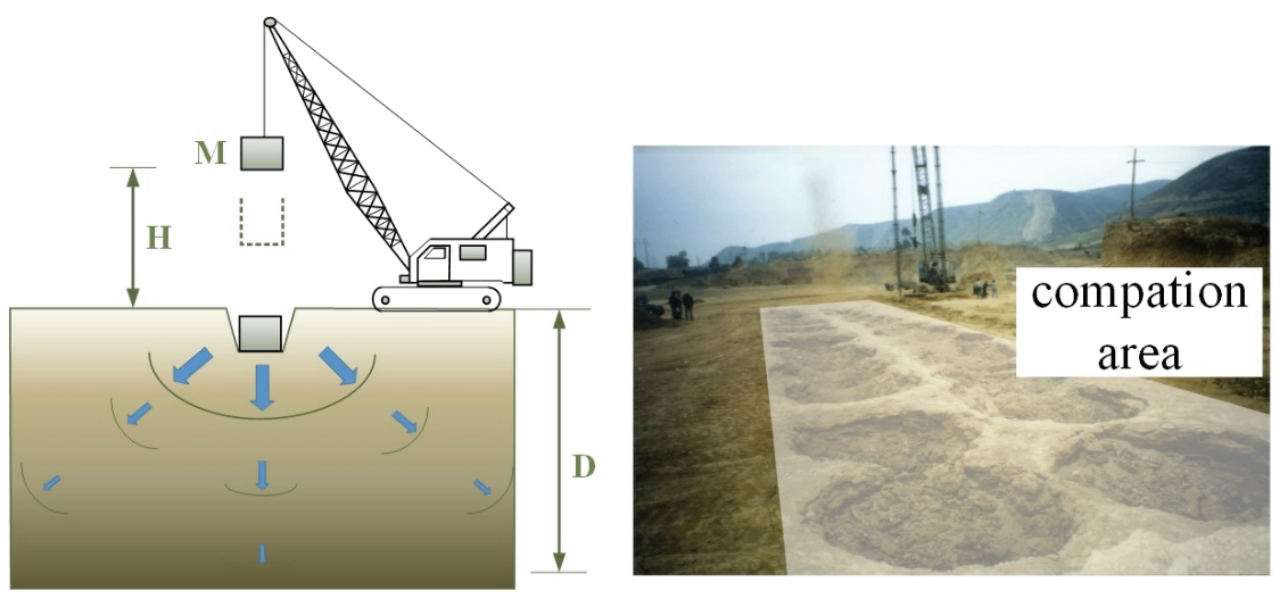

Figure 9 - Dynamic Compaction Test Hoisting Equipment and Hammer [29]

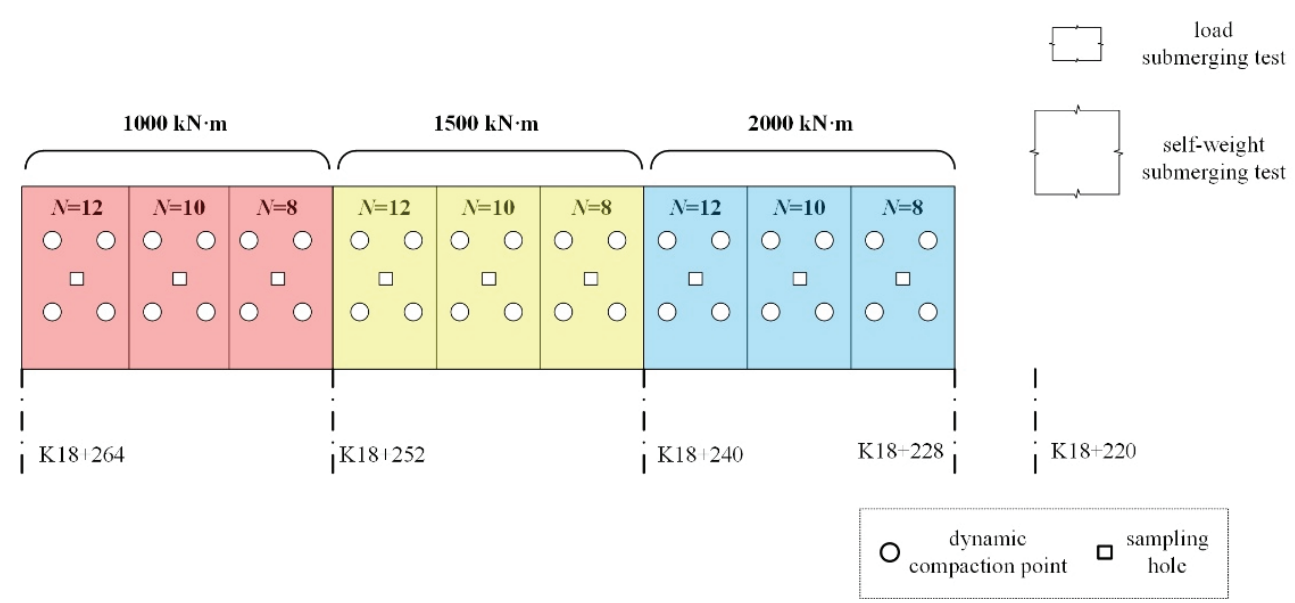

Figure 10 - Test Design

\subsection{Compaction Settlement}

Fig. 11 is the mean value and standard deviation results of relative settlement for the 3 energy levels, and the curves were fitted from the mean value. It can be seen that the compaction settlement of the first drop increases with the energy levels, for $1000 \mathrm{kN} \cdot \mathrm{m}$ it is $20 \mathrm{~cm}$, and for $1500 \mathrm{kN} \cdot \mathrm{m}$ it is $30 \mathrm{~cm}$, for $2000 \mathrm{kN} \cdot \mathrm{m}$ it is $45 \mathrm{~cm}$. And when the number of drops $(N)$ increases, the relative settlement decreases as a power function. So according to the function, the relative settlement of each drop can be calculated. According to the Chinese Technical Code [28], it has noted that for energy levels lower than $4000 \mathrm{kN} \cdot \mathrm{m}$, when the average settlement for the last two drops is less than $5 \mathrm{~cm}$, compaction can be finished. As the dark 
dotted line shows, for the $1000 \mathrm{kN} \cdot \mathrm{m}$ level, $N$ is 5 , and for the 1500 and $2000 \mathrm{kN} \cdot \mathrm{m}$ levels, $N$ is 8 .

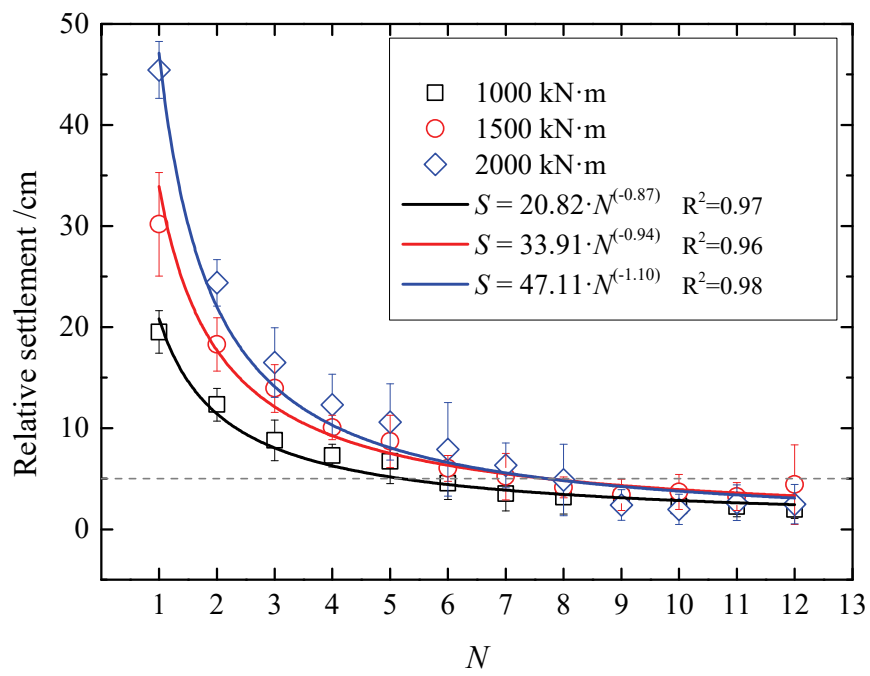

Figure 11. Relationship between the Relative Settlement and Number of Drops (N) for the three Energy Levels: $1000 \mathrm{kN} \cdot \mathrm{m}, 1500 \mathrm{kN} \cdot \mathrm{m}$ and $2000 \mathrm{kN} \cdot \mathrm{m}$

\subsection{Comparison of Collapsibility Elimination}

Samples of different depths were taken by drilling and tested indoors to acquire the collapsibility coefficient as defined in formula (1). Fig. 12 illustrates that after compaction, the collapsibility of the loess has been mainly eliminated, except for some abnormal data points, which may be from the influence of the sampling error. The sampling hole is in the

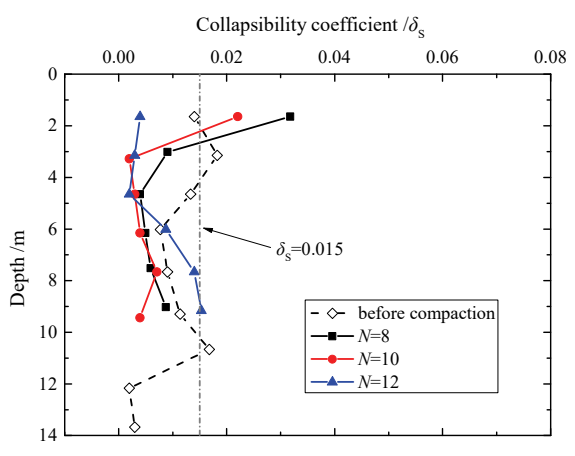

(a) $1000 \mathrm{kN} \cdot \mathrm{m}$

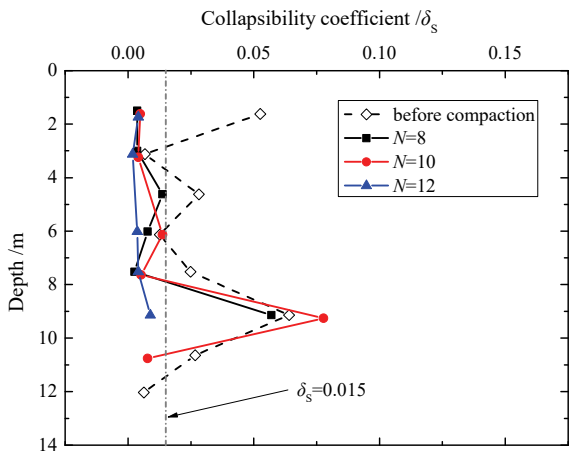

(b) $1500 \mathrm{kN} \cdot \mathrm{m}$ 


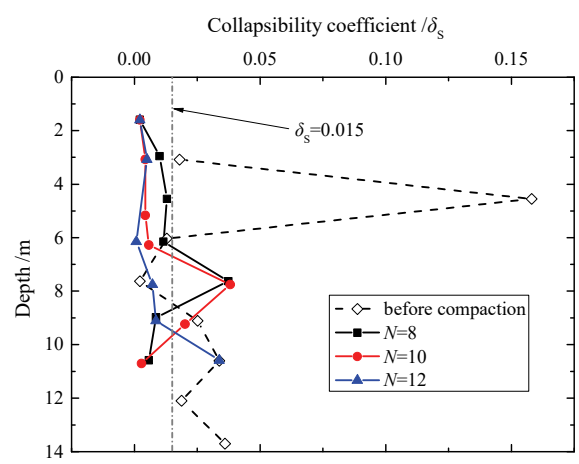

(c) $2000 \mathrm{kN} \cdot \mathrm{m}$

Figure 12 - Relationship between the Collapsibility Coefficient and N for the three Energy Levels: $1000 \mathrm{kN} \cdot \mathrm{m}, 1500 \mathrm{kN} \cdot \mathrm{m}$ and $2000 \mathrm{kN} \cdot \mathrm{m}$

middle of the 4 compaction points (Fig. 10), and it may be disturbed by the compaction vibration, which leads to the discrepancy of the soil in the middle. For the higher energy level, with the increase in the number of drops $(N)$, the effect of eliminating collapsibility becomes more obvious. For $1000 \mathrm{kN} \cdot \mathrm{m}$, the difference between 8,10 and 12 drops is not obvious, and the maximum effective depth is approximately $5 \mathrm{~m}$. For $1500 \mathrm{kN} \cdot \mathrm{m}$, the maximum effective depth for 8,10 and 12 drops is $6 \mathrm{~m}$. For $2000 \mathrm{kN} \cdot \mathrm{m}$, the maximum effective depth for 8 and 10 drops is approximately $6 \mathrm{~m}$, and it is $7 \mathrm{~m}$ for 12 drops.

\subsection{Comparison of the CPT}

For the CPT results, the dotted line is the result before compaction, and the solid line is the result after compaction, and $P_{\mathrm{s}}$ is the specific penetration resistance. Fig. 13 shows that, for $1000 \mathrm{kN} \cdot \mathrm{m}$, the specific penetration resistance has been improved in $0-6 \mathrm{~m}$, and beyond 6 $\mathrm{m}$, the effect of the improvement is not obvious. For $N=10$, the maximum effective depth is approximately $5 \mathrm{~m}$, and for $N=12$, it is approximately $6 \mathrm{~m}$. Therefore, for the $1000 \mathrm{kN} \cdot \mathrm{m}$ energy level, the maximum effective depth is approximately $5-6 \mathrm{~m}$, and increasing the $N$ from 8 to 12 is not obvious for the effect of improvement.

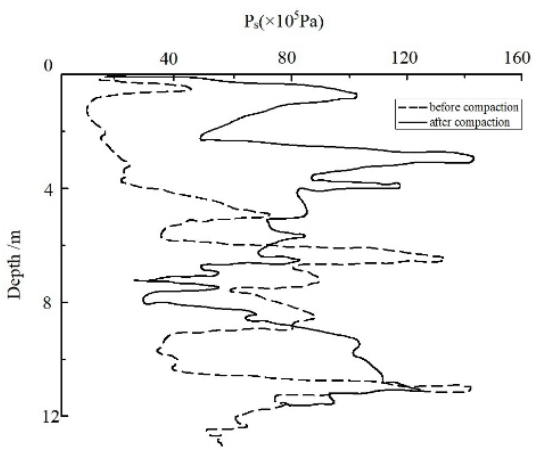

(a) $N=8$

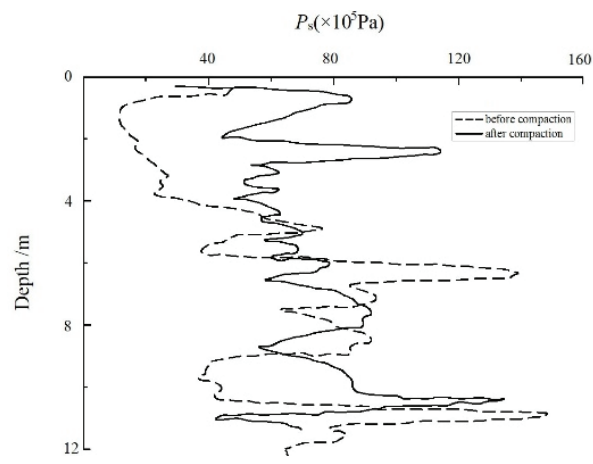

(b) $N=10$ 
Application of the Dynamic Compaction Method for Ground Improvement of Collapsible ...

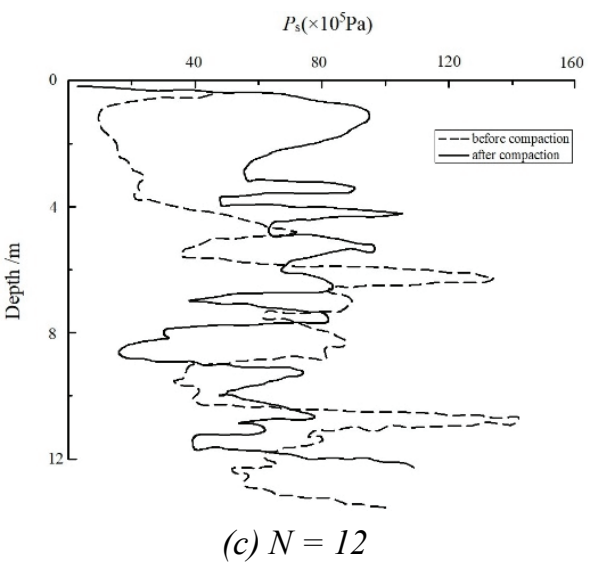

Figure 13 - CPT Curves for Different $N$ at an Energy Level of $1000 \mathrm{kN} \cdot \mathrm{m}$
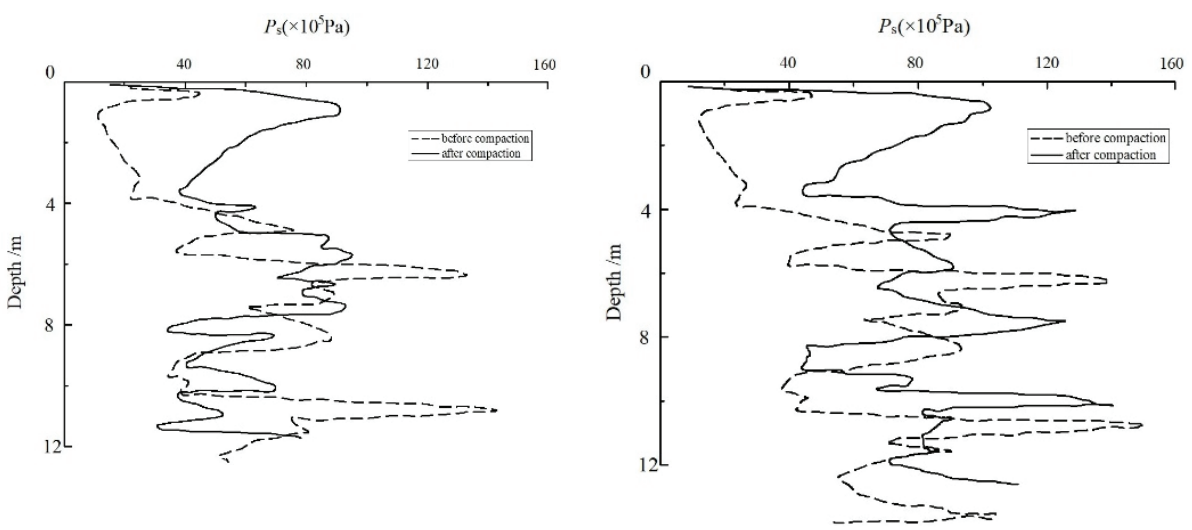

(a) $N=8$

(b) $N=10$

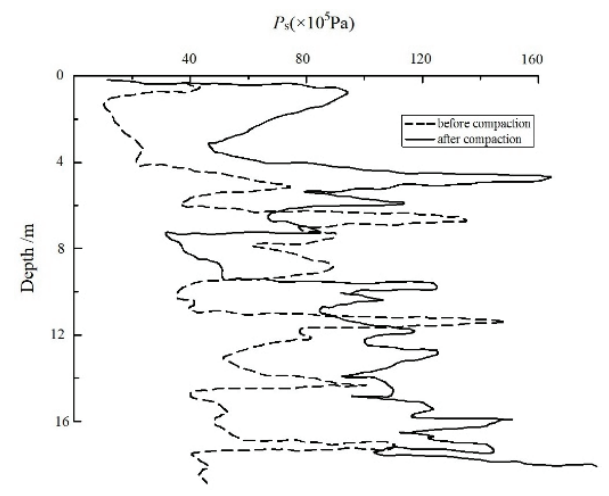

(c) $N=12$

Figure 14 - CPT Curves for Different $N$ at an Energy Level of $1500 \mathrm{kN} \cdot \mathrm{m}$ 
Fig. 14 illustrates the CPT results for $1500 \mathrm{kN} \cdot \mathrm{m}$. According to the shape of the curves, for the sharp points, it is possible that the probe cone tip touched a hard object. Therefore, the maximum effective depth is approximately $6 \mathrm{~m}$.

Fig. 15 illustrates that for 8 drops, the maximum effective depth is $6 \mathrm{~m}$. For 10 and 12 drops, the specific penetration resistance at 0-7 $\mathrm{m}$ increases significantly, so the maximum effective depth for 12 drops is $7 \mathrm{~m}$.

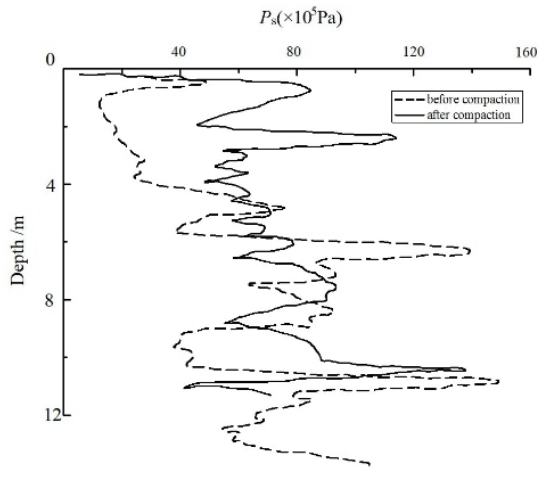

(a) $N=8$

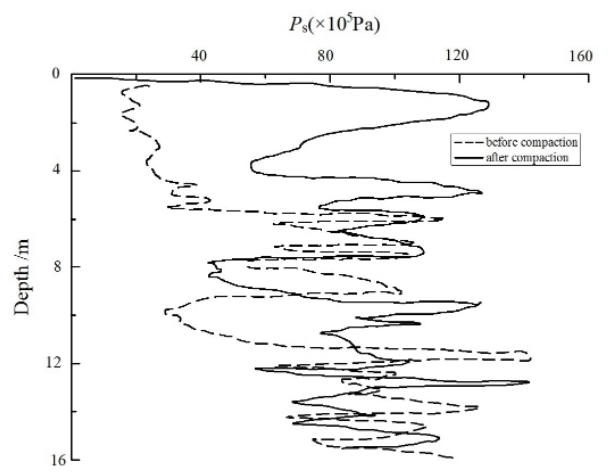

(b) $N=10$

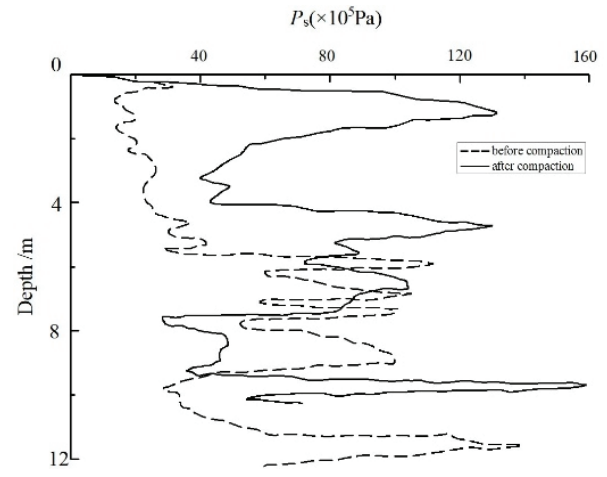

(c) $N=12$

Figure 15 - CPT Curves for Different $N$ at an Energy Level of $2000 \mathrm{kN} \cdot \mathrm{m}$

The indoor collapsibility tests and CPT tests indicate that the two results are consistent. For the energy levels of $1000 \mathrm{kN} \cdot \mathrm{m}$ and $1500 \mathrm{kN} \cdot \mathrm{m}$, the effect of improvement is not significant as the number of drops $(N)$ increases. The maximum effective depth for $1000 \mathrm{kN} \cdot \mathrm{m}$ is about $5-6 \mathrm{~m}$, and for $1500 \mathrm{kN} \cdot \mathrm{m}$, it is $6 \mathrm{~m}$. For $2000 \mathrm{kN} \cdot \mathrm{m}$, the maximum effective depth increases with the number of drops where it is $6 \mathrm{~m}$ for $N=8,6-7 \mathrm{~m}$ for $N=10$, and $7 \mathrm{~m}$ for $N=12$. 


\section{CONCLUSION}

For the construction of high-grade highway subgrades in collapsible loess regions in Qinghai, China, where differential settlement of collapsibility always occurs, a series of loess property tests were conducted, and various collapsibility influencing factors and in situ collapsible settlement regularities were systematically discussed. Accordingly, the dynamic compaction method was chosen to improve the foundation, and the effect of the treatment was evaluated. The results can be concluded as follows:

(1) The loess collapsibility in situ tests indicate that the soil in the test region is self-weight collapsible loess. The maximum settlement in the self-weight submerging test is $22.4 \mathrm{~cm}$ and that in the load submerging test is $23.9 \mathrm{~cm}$; they are all in the centre of the test pit. For deep collapsible settlement, with increasing depth, the collapsibility increases to a maximum at $1.5 \mathrm{~m}$ and then gradually decreases. In addition, the collapsible deformation can be divided into two stages: the collapsible deformation stage and the reconsolidation stage.

(2) For economy and applicability, the dynamic compaction method was applied for collapsible loess treatment. By fitting, the relationship between relative settlement and number of drops $(N)$ at different energy levels is obtained. The optimization of $N$ is also conducted at different energy levels, according to the quality control standards of the Chinese Technical Code (JGJ 79-2012), $N$ is 5 for $1000 \mathrm{kN} \cdot \mathrm{m}$ and $N$ is 8 for $1500 \mathrm{kN} \cdot \mathrm{m}$ and 2000 $\mathrm{kN} \cdot \mathrm{m}$.

(3) Loess collapsibility laboratory tests and in situ CPT tests were utilized for the evaluation of the compaction effect; for energy levels of $1000 \mathrm{kN} \cdot \mathrm{m}$ and $1500 \mathrm{kN} \cdot \mathrm{m}$, increasing the number of drops $(N)$ from 8 to 12 is ineffective. The maximum effective depth for $1000 \mathrm{kN} \cdot \mathrm{m}$ is about $5-6 \mathrm{~m}$, and for $1500 \mathrm{kN} \cdot \mathrm{m}$, it is $6 \mathrm{~m}$. For $2000 \mathrm{kN} \cdot \mathrm{m}$, the maximum effective depth increases with the number of drops $(N)$, where the depth is $6 \mathrm{~m}$ for $N=8,6-7 \mathrm{~m}$ for $N=10$, and $7 \mathrm{~m}$ for $N=12$.

\section{Acknowledgments}

The work in this paper was substantially supported by the Qinghai provincial authority of high-grade highway construction management and Chang'an University.

\section{References}

[1] Qian H. X, Luo Y. S. Collapsible loess subsoil. Beijing: China Architecture \& Building Press, 1985.

[2] Yao Z. H., Huang X. F., Chen Z. H., Zhang J. H., Comprehensive submerging tests on self-weight collapse loess with heavy section in Lanzhou region. Chinese Journal of Geotechnical Engineering, 1(34):65 - 74, 2012.

[3] Liu Z. D, Mechanics and engineering of loess. Xi'an: Shanxi Sciences and Technology Press, 1996.

[4] Chen Z. H., Xu Z. H., Liu Z. D., Some problems of collapsed loess. Chinese Journal of civil Engineering, 19(3):62 - 69, 1986. 
[5] Shao S. J., Yang C. M., Ma X. T. et al, Correlation analysis of collapsible parameters and independent physical indices of loess. Rock and Soil Mechanics, 34 Supp(2): 27 $34,2013$.

[6] Gao G. R., A structure theory for collapsing deformation of loess soils. Chinese Journal of Geotechnical Engineering, 12(4): 1 - 10, 1990.

[7] Kovacs, J; Raucsik, B, Varga, A., et al, Clay mineralogy of red clay deposits from the central Carpathian Basin (Hungary): implications for Plio-Pleistocene chemical weathering and palaeoclimate. Turkish Journal of Earth Sciences, (22): 414 - 426, 2013.

[8] Walsh K., Houston W., Houston S. L., Evaluation of in-place witting using soil suction measurement. Geotechnical Engineering, 119(5):862 - 873, 1993.

[9] Miao T. D., Liu Z. Y., Ren J. S., Deformation mechanism and constitutive relation of collapsed loess. Chinese Journal of Geotechnical Engineering, 21(4):383 - 387, 1999.

[10] Liao S. X., Study on pre-submerging of collapsible loess. Nonferrous Metallurgy Construction, 3(2): 1 - 13, 1983.

[11] Qian H. J., Zhu M., Xie S., Experimental study on the regularities of collapsible deformation of loess foundation in Hejin, Shanxi. Chinese Journal of Geotechnical Engineering, 14(6): 1 - 9, 1992.

[12] Li D. Z., He Y. H., Sui G. X., Study and test on immersion of Q2 loess in large area. Chinese Journal of Geotechnical Engineering, 15(2): 1 - 11, 1993.

[13] Houston S. L., Foundations and pavements on unsaturated soils. Proceeding 1st International Conference on Unsaturated Soils, Paris, France, 1995.

[14] Huang X. F., Chen Z. H., Ha S., Xue S. G., Sun S. X., Xu Y. M., Jin X. J., Zhu Y. Q., Large area field immersion test on characteristics of deformation of self-weight collapse loess under overburden pressure. Chinese Journal of Geotechnical Engineering, 28(3): $382-389,2006$.

[15] Lyu X. J., Gong X. N., Li J. G., Research on parameters of construction with dynamic compaction method. Rock and Soil Mechanics, 27(9): 1628 - 1633, 2006.

[16] Xing Y. D., Wang C. M., Zhang L. X., Effect analysis of dynamic ramming for collapsible loess roadbed in west of Liaoning. Journal of Liaoning Technical University (Natural Science), 27(3): $371-373,2008$.

[17] Zhan J. L., Shui W. H., Application of high energy level dynamic compaction to ground improvement of collapsible loess for petrochemical project. Rock and Soil Mechanics, 30(S2): $469-472,2009$.

[18] Huang X. F., Chen Z. H., Fang X. W., Zhu Y. Q., Guo J. F., Wei X. F., Study on foundation treatment thickness and treatment method for collapse loess with large thickness. Chinese Journal of Rock Mechanics and Engineering, 26(S2): 4332 - 4338, 2007. 
[19] Hu C. M., Mei Y., Wang X. Y., Experimental research on dynamic compaction parameters of collapsible loess foundation in Lishi region. Rock and Soil Mechanics, 33(10):2903 - 2909, 2012.

[20] Code for building construction in collapsible loess regions, GB/ 50025-2004, China Architecture and Building Press

[21] Mitchell J. J., Kenichi S., Fundamentals of soil behavior. John Wiley \& Sons Inc, Hoboken, New Jersey, 2005.

[22] Xie D. Y., Xing Y. C., Soil Mechanics for Loess Soils. Beijing: Higher Education Press, 2016.

[23] Liu Z. D., Li J., Guo Z. Y., Rao W. Y., Deformation behaviours and deformation parameter of loess in Shanxi district. Chinese Journal of Geotechnical Engineering, 6(3): $24-34,1984$.

[24] Lin Y., Study on engineering characteristics of deep layer collapsible loess in Pengjiaping area of Lanzhou City, Lanzhou University, 2019

[25] Wang J. Q., Lei S. Y., Li X. L., Wang Y. M., Liu Z., Wang X. G., Correlation of wet collapsibility coefficient and physical property parameters of loess. Coal Geology and Exploration, 41(3): $42-50,2013$.

[26] Huang X. F., Yang X. H., A study progress on in-situ soaking test on collapsible loess. Rock and Soil Mechanics, 34(S2): 222 - 228, 2013.

[27] Xu Z. J., Zhang Y. N., Dynamic compaction and dynamic compaction replacement methods for reinforcing foundation. Beijing: China Machine Press, 2004.

[28] Technical code for ground treatment of buildings. Ministry of Housing and UrbanRural Development of the People's Republic of China. 2012, (JGJ 79-2012).

[29] Lukas R. G., Delayed soil improvement after dynamic compaction. Ground Improvement, Ground Reinforcement, Ground Treatment. Published by the ASCE, 1997: 409 - 420, 1997. 